\title{
Konsumsi Sayur dan Buah pada Siswa Sekolah Dasar (Studi pada Makan Siang Sekolah dan Bekal)
}

\section{Vegetable and Fruit Consumption of Primary School Children (A Study of School Lunch and Packed Lunch)}

\author{
Diani Zafira, Farapti Farapti*
}

\begin{abstract}
ABSTRAK
Latar belakang: Konsumsi sayur dan buah di Indonesia tergolong rendah dibanding anjuran World Health Organization $400 \mathrm{~g} /$ hari. Upaya meningkatkan asupan sayur dan buah anak usia sekolah ialah melalui program makan siang sekolah dan bekal.

Tujuan: Menganalisis perbedaan konsumsi sayur dan buah antara kelompok makan siang sekolah dan bekal.

Metode: Penelitian Cross-sectional ini melibatkan 155 siswa yang dibagi menjadi 47 siswa kelompok makan siang sekolah dan 108 siswa kelompok bekal. Penelitian dilakukan di SD Muhammadiyah 4 Surabaya. Kuesioner yang digunakan adalah food recall selama $2 \times 24$ jam, observasi asupan sayur dan buah ketika makan siang dan asupan sehari dibandingkan antara makan siang sekolah dan bekal. Analisis menggunakan uji independen $t$-test.

Hasil: Rata-rata konsumsi sayur dan buah saat makan siang pada kelompok makan siang sekolah dan kelompok bekal menunjukkan perbedaan signifikan yakni sayur $(p<0,001)$ dan buah $(p<0,001)$. Jumlah konsumsi sayur dan buah pada kelompok makan siang sekolah rata-rata 26,66 g dan 25,53 g dan kelompok bekal hanya 5,09 g dan 3,24 g. Rata-rata konsumsi sayur dan buah sehari tidak ada perbedaan pada 2 kelompok baik sayur $(p=0,322)$ dan buah $(p=0,473)$. Jumlah konsumsi sayur dan buah sehari kelompok makan siang sekolah ialah $28,88 \mathrm{~g}$ dan $31,81 \mathrm{~g}$, sedangkan pada kelompok bekal hanya $18,08 \mathrm{~g}$ dan $25,46 \mathrm{~g}$.

Kesimpulan: Terdapat perbedaan konsumsi sayur dan buah antara kelompok makan siang sekolah dengan bekal. Perlu adanya standar makan siang sekolah dan makanan bekal untuk meningkatkan asupan dan mengurangi sisa sayur dan buah pada makanan siang sekolah.
\end{abstract}

Kata Kunci: sayur dan buah, konsumsi, anak, makan siang sekolah, bekal.

\section{ABSTRACT}

Background: The consumption for vegetable and fruit in Indonesia was lower than recommendation World Health Organization $400 \mathrm{~g} /$ day. School lunch and packed lunch could increased consumption of vegetable and fruit.

Objective: To analyze differences vegetable and fruit consumption between school lunch and packed lunch group.

Method: This was a cross-sectional study involving 155 students with 47 sampels for school lunch and 108 sampels for packed lunch group in SD Muhammadiyah 4 Surabaya. Respondents were interviewed with questioner using food recall method for $2 \times 24$ hours, observed intake of vegetables and fruit during lunch and intake a day compared between school lunch and packed lunches. Data were analyzed using independent $t$-test.

Result: Average consumption of vegetables and fruit between two groups was significant, vegetables $(p<0.001)$ and fruit $(p<0.001)$. The amount of vegetable and fruit consumption in the school lunch group averages $26.66 \mathrm{~g}$ and $25.53 \mathrm{~g}$ and packed lunch groups only $5.09 \mathrm{~g}$ and $3.24 \mathrm{~g}$. There was no difference in two groups for consumption of vegetables $(p=0.322)$ and fruit $(p=0.473)$. Amount of consumption of vegetables and fruits a day in school lunch group was $28.88 \mathrm{~g}$ and $31.81 \mathrm{~g}$, while in packed lunch group only $18.08 \mathrm{~g}$ and $25.46 \mathrm{~g}$.

Conclusions: There were differences of the consumption of vegetables and fruits between two groups. School lunch and packed lunch standard to increase intake and reduce vegetables and fruits waste in school lunch is needed.

Keywords: vegetable and fruit, consumption, children, school lunch, packed lunch.

\author{
*Koresponden : \\ Farapti Farapti \\ farapti@fkm.unair.ac.id \\ Departemen Gizi Kesehatan,Fakultas Kesehatan Masyarakat - Universitas Airlangga, Indonesia
}




\section{PENDAHULUAN}

Salah satu masalah gizi pada anak usia sekolah ialah kegemukan terutama yang berada di wilayah perkotaan. Prevalensi gizi lebih anak usia sekolah (5-12 tahun) mengalami peningkatan. Data Riskesdas menunjukkan prevalensi gizi lebih di Indonesia tahun 2013 sebesar 18,8\% ${ }^{1}$ meningkat pada tahun 2018 menjadi $20 \% .^{2}$ Di Jawa Timur prevalensi gizi lebih tahun 2013 yaitu $19,3 \%^{1}$ meningkat menjadi $24,1 \%$ di tahun 2018. ${ }^{2}$ Sedangkan, prevalensi gizi lebih di Surabaya tahun 2013 sebesar 22,2\%. ${ }^{3}$ Kegemukan terjadi ketika kelebihan konsumsi pangan tinggi energi, lemak, gula dan garam namun rendah pada konsumsi sayur dan buah. ${ }^{4}$ Padahal sayur dan buah mempunyai banyak manfaat seperti mengurangi risiko penyakit degeneratif seperti kardiovaskuler, ${ }^{5}$ hipertensi dan stroke. ${ }^{6}$ Namun konsumsi sayur dan buah pada anak usia sekolah masih tergolong rendah. Berdasarkan hasil Riskesdas 2018 sebanyak 95,5\% penduduk Indonesia yang mengkonsumsi sayur dan buah belum sesuai anjuran 5 porsi/hari, ${ }^{2}$ data ini meningkat dari tahun 2013 sebanyak 93,5\%. ${ }^{1}$ Menurut WHO anjuran konsumsi sayur dan buah sebanyak 400 g/hari yakni 250 g sayur dan 150 g buah. $^{7}$

Salah satu upaya untuk meningkatkan asupan sayur dan buah pada anak adalah membentuk pola makan sehat melalui makanan siang sekolah. Seperti di Jepang yang lebih dikenal dengan istilah Shokuiku yang merupakan kegiatan pendidikan untuk bertanggung jawab pada makan siang dan belajar mengenai gizi seimbang serta bertujuan untuk menurunkan angka obseitas anak. ${ }^{8,9}$ Namun sisa makan siang sekolah paling banyak berasal dari sayur dan buah. ${ }^{10-15}$ Penelitian sebelumnya menyatakan bahwa anak usia sekolah yang berusia lebih muda akan lebih banyak menyisakan makanan $^{12}$ dan begitupun bila dibandingkan dengan siswa Sekolah Menengah Pertama (SMP). ${ }^{10}$ Ketika menyisakan makanan yang tersaji sama saja hal ini membuang zat gizi yang seharusnya bisa diserap oleh tubuh. ${ }^{16}$ Untuk memenuhi kebutuhan makan siang selama di sekolah, belum semua sekolah di Indonesia bisa menerapkan kegiatan ini sehingga ada pula siswa yang membawa bekal dari rumah. Komponen zat gizi pada makanan bekal akan berbeda dengan makan siang yang sudah ditetapkan standar oleh sekolah. Sayuran memiliki jumlah yang paling banyak terbuang dintara makanan lainnya, hal ini dipengaruhi oleh tingkat kesukaan yang rendah, pola konsumsi siswa, pemahaman tentang zat gizi dan makanan yang terbuang karena akan berpengaruh pada penerimaan makanan setiap siswa. ${ }^{17}$

Lokasi penelitian di SD Muhammadiyah 4 Pucang Surabaya dimana sekolah ini merupakan sekolah dengan sistem full day, sehingga sekolah menyediakan fasilitas makan siang sekolah namun tidak bersifat wajib. Hampir separuh siswa di sekolah membawa bekal dari rumah dan hanya $20 \%$ yang mengikuti makan siang sekolah. Konsumsi sayur dan buah di Indonesia masih rendah, terutama pada usia sekolah dimana kelompok makanan ini kurang disukai anak. Padahal saat masa pertumbuhan zat mikronutrien pada sayur dan buah dibutuhkan dalam perkembangan fisik, sistem imun dan hormon ${ }^{7}$ serta salah satu upaya preventif mencegah penyakit degeneratif di usia dewasa. ${ }^{6}$ Penelitian ini bertujuan untuk membandingkan konsumsi sayur buah pada kelompok makan siang sekolah dan pada makanan bekal yang dibawa oleh siswa.

\section{METODE}

Penelitian ini menggunakan desain penelitian cross sectional. Responden penelitian ialah siswa laki-laki dan perempuan kelas 4-5 yang mengikuti makan siang sekolah dengan siswa yang membawa bekal makan di SD Muhammadiyah 4 Pucang Surabaya dan setuju untuk berpartisipasi. Siswa dipilih secara system random sampling berdasarkan kelas yang diizinkan oleh pihak sekolah yang telah mengisi lembar persetujuan dan bersedia. Total responden sebanyak 155 siswa dengan 47 siswa yang mengikuti program makan siang sekolah dan 108 siswa yang membawa bekal makan siang. Besar sampel masing-masing kelompok ditentukan dengan perhitungan proportional sampling.

Makanan responden diobservasi pada saat jam makan siang selama 5 hari pada kelompok makan siang sekolah sedangkan pada kelompok bekal diobservasi pada 2 hari yang berbeda dan dilakukan wawancara asupan sehari melalui metode food recall $2 \times 24$ jam kemudian dicatat. Berat makanan ketika makan siang diestimasi secara visual. Besar porsi diestimasi menggunakan buku foto makanan yang diterbitkan oleh Kementerian Kesehatan hasil studi diet total 2014. Sisa makanan pada kelompok makan siang sekolah diobservasi dan dicatat selama 5 hari menggunakan metode Comstock yang dibandingkan dengan standar porsi makan siang sekolah. Hasil estimasi dianalisis statistik menggunakan software SPSS versi 24 . Perbedaan rata-rata tiap kelompok bila terdistribusi normal dianalisis menggunakan uji independen t-test, sedangkan bila tidak normal menggunakan uji Mann Whitney. Jumlah sayur dan buah yang dikonsumsi dibandingkan dengan standar WHO yaitu $400 \mathrm{~g} /$ hari dengan rincian $250 \mathrm{~g}$ sayuran dan $150 \mathrm{~g}$ buah-buahan. ${ }^{7}$ Kaji etik telah disetujui oleh Komisi Etik Fakultas Kesehatan Masyarakat Universitas Airlangga dengan no. 441-KEPK.

\section{HASIL PEMBAHASAN}

Karakteristik responden meliputi usia dan jenis kelamin (Tabel 1) Hampir seluruh responden berjenis kelamin perempuan $(51,61 \%)$ dengan rerata usia paling besar adalah 10 tahun untuk kelompok makan siang sekolah (42,55\%) dan kelompok bekal (48,15\%).

Selama 5 hari menu makan siang diobservasi, tidak disediakan menu buah sehingga buah hanya mencul sekali sebagai pengganti sayur. Pada tabel 2 menunjukkan bahwa rerata responden pada kelompok makan siang sekolah yang mengkonsumsi sayuran dan buah secara penuh masing-masing hanya $23,4 \%$ dan $46,81 \%$ sedangkan yang mengkonsumsi sayur dan buah separuh sebesar 40,43\% dan 44,68\%. Seperti penelitian sebelumnya dimana dua per tiga siswa tidak mengkonsumsi buah pada makan siang, dan hanya 3\% dari total yang menghabiskan seporsi buah. Sedangkan untuk sayur hanya $6 \%$ yang yang menghabiskan 1 porsi dan $23 \%$ yang tidak mengkonsumsai sayur sama sekali. ${ }^{18}$ Tujuan diadakannya program makan siang sekolah adalah untuk memenuhi kebutuhan makan siang siswa sebanyak $30 \%$ dari kebutuhan sehari, ${ }^{19}$ namun berdasarkan hasil data yang didapat masih ada siswa yang tidak 
mengkonsumsi makanan yang telah disajikan sehingga kebutuhan makan siang tidak tercukupi.

Berdasarkan data pada kelompok bekal, hanya $17(15,7 \%)$ dari 108 siswa yang membawa sayuran dan 5 $(4,6 \%)$ dari 108 siswa yang membawa buah-buahan. Sebesar 4 siswa $(3,7 \%)$ membawa sayur dengan jumlah mencapai $50 \mathrm{~g}$ dan untuk buah-buahan hanya 3 siswa (2,78\%) yang membawa $50 \mathrm{~g}$ dan 2 siswa (1,85\%) yang membawa lebih dari $50 \mathrm{~g}$. Bila dilihat dari perbandingan antara menu pada makan siang sekolah terdapat menu sayur atau buah setiap harinya dengan jumlah $50 \mathrm{~g}$ setiap porsinya, sedangkan pada menu bekal makan yang dibawa dari rumah masih sedikit sekali yang membawa sayur atau buah. Perbedaan ini terjadi karena tidak adanya standar makanan yang harus dibawa ke sekolah, sehingga perlu adanya standar makanan untuk meningkatkan konsumsi sayur dan buah pada anak sekolah. Sedikitnya jumlah siswa yang membawa sayur dan buah pada kelompok bekal serupa dengan penelitian yang pernah dilakukan di Inggris dimana hanya $5(8,6 \%)$ dari 58 orang siswa yang membawa buah dan hanya 3 $(6,8 \%)$ yang membawa sayur. ${ }^{20}$

Tabel 1 Distribusi Karakteristik Responden di SD Muhammadyah 4 Pucang Surabaya

\begin{tabular}{|c|c|c|c|c|c|c|c|}
\hline \multirow{2}{*}{ Karakteristik Responden } & \multicolumn{3}{|c|}{ Makan Siang Sekolah } & \multicolumn{2}{|c|}{ Bekal } & \multicolumn{2}{|c|}{ Total } \\
\hline & $n=47$ & & $\%$ & $n=108$ & $\%$ & $n$ & $\%$ \\
\hline \multicolumn{8}{|l|}{ Usia } \\
\hline 9 tahun & 12 & 25,53 & & 20 & 18,52 & 32 & 20,65 \\
\hline 10 tahun & 20 & 42,55 & & 52 & 48,15 & 72 & 46,45 \\
\hline 11 tahun & 14 & 29,79 & & 33 & 30,56 & 47 & 30,32 \\
\hline 12 tahun & 1 & 2,13 & & 3 & 2,78 & 4 & 2,58 \\
\hline \multicolumn{8}{|l|}{ Jenis Kelamin } \\
\hline Laki-laki & 29 & 61,7 & & 51 & 47,22 & 80 & 51,61 \\
\hline Perempuan & 18 & 38,3 & & 57 & 52,78 & 75 & 48,39 \\
\hline
\end{tabular}

Ketiadaan kebijakan untuk membawa sayur dan buah pada menu bekal makan siang ke sekolah menyebabkan orangtua hanya membawa makanan yang diinginkan oleh siswa. Pada usia sekolah masalah pilihpilih makanan terutama menolak untuk konsumsi sayur dan buah sering terjadi. Faktor yang mendasari anak untuk pilih-pilih makanan yaitu variasi jenis makanan dibandingkan jumlah makanan yang disajikan. ${ }^{21}$ Anak yang pilih-pilih makanan (picky eater) memiliki asupan vitamin dan mineral yang signifikan lebih rendah, begitupun pada kadar magnesium dan zat besi dalam darah. ${ }^{22}$ Perilaku pilih-pilih makanan salah satunya dipengaruhi oleh kebiasaan makan orang tua. Anak yang perilaku makan orang tuanya memilih-milih makanan beresiko mengalami Picky Eater 10,1 kali lebih besar dibandingkan anak-anak yang orangtuanya tidak pemilih pada makanan. ${ }^{23}$

Tabel 2 Rata-rata asupan sayur dan buah selama makan siang

\begin{tabular}{|c|c|c|c|c|c|c|c|c|c|}
\hline \multirow{3}{*}{ Gram } & \multirow{3}{*}{ Porsi } & \multicolumn{4}{|c|}{$\begin{array}{l}\text { makan siang sekolah } \\
\qquad \mathrm{N}=47\end{array}$} & \multicolumn{4}{|c|}{$\begin{array}{c}\text { bekal } \\
N=108\end{array}$} \\
\hline & & \multicolumn{2}{|c|}{ Sayur } & \multicolumn{2}{|c|}{ Buah } & \multicolumn{2}{|c|}{ Sayur } & \multicolumn{2}{|c|}{ Buah } \\
\hline & & $\mathrm{n}$ & $\%$ & $\mathrm{n}$ & $\%$ & $\mathrm{n}$ & $\%$ & $\mathrm{n}$ & $\%$ \\
\hline 0 & 0 & 6 & 12,77 & 21 & 44,68 & 91 & 84,26 & 103 & 97,1 \\
\hline $1-12,5$ & $1 / 4$ & 5 & 10,64 & 0 & 0 & 0 & 0 & 0 & 0 \\
\hline $12,6-25$ & $1 / 2$ & 19 & 40,43 & 4 & 8,51 & 6 & 5,56 & 0 & 0 \\
\hline $25,1-37,5$ & $3 / 4$ & 6 & 12,77 & 0 & 0 & 7 & 6,48 & 0 & 0 \\
\hline $37,6-50$ & 1 & 11 & 23,4 & 22 & 46,81 & 4 & 3,7 & 3 & 2,78 \\
\hline$>50$ & $>1$ & & & & & & & 2 & 1,85 \\
\hline
\end{tabular}

Selama 5 hari observasi pada makan siang sekolah, menu sayur merupakan makanan yang paling banyak tidak dikonsumsi dan terbuang. Rata-rata sayur yang tidak dikonsumsi hampir separuh dari yang disajikan. Porsi sayur disetiap menu yaitu sekitar $50 \mathrm{~g}$. Jumlah sisa sayur dalam 5 hari observasi berturut-turut terlihat pada Gambar 1 yaitu 40\%, 44\%, 60\% dan $44 \%$. Hasil menunjukkan bahwa menu buah hanya terdapat sekali untuk menggantikan sayur, yaitu pada hari ke-5.
Jumlah sisa buah tidak jauh berbeda dengan sayur yaitu sebanyak 49\%. Selama 1978-2015 sayur dan buah merupakan komponen makanan yang sering difokuskan untuk diteliti karena paling banyak bersisa pada program makan siang sekolah. ${ }^{17}$

Hasil rata-rata jumlah konsumsi sayur dan buah saat makan siang pada kelompok makan siang sekolah dan kelompok bekal menunjukkan perbedaan yang signifikan yakni sayur $(p=0,000)$ dan buah $p=(0,000)$. 
Jumlah konsumsi sayur dan buah pada kelompok makan siang sekolah rata-rata mencapai 26,66 g dan 25,53 g, sedangkan pada kelompok bekal hanya 5,09 g sayur dan 3,24 g buah. Jika dibandingkan dengan anjuran WHO maka konsumsi sayur dan buah pada kelompok makan siang sekolah hanya $11 \%$ dan $17 \%$ sedangkan konsumsi pada kelompok bekal masing-masing hanya mencapai $2 \%$ dari yang dianjurkan. Namun bila dilihat dari total konsumsi sehari tidak ada perbedaan pada 2 kelompok baik konsumsi sayur $p=(0,322)$ dan buah $p=(0.473)$. Jumlah konsumsi sayur dan buah sehari di kelompok makan siang sekolah ialah $28,88 \mathrm{~g}$ dan $31,81 \mathrm{~g}$, sedangkan pada kelompok bekal hanya $18,08 \mathrm{~g}$ dan $25,46 \mathrm{~g}$. Berdasarkan rekomendasi WHO, responden pada kelompok makan siang hanya bisa memenuhi $12 \%$ sayur dan $21 \%$ buah sedangkan pada kelompok bekal hanya dapat memenuhi $7 \%$ sayur dan $17 \%$ buah dalam sehari.

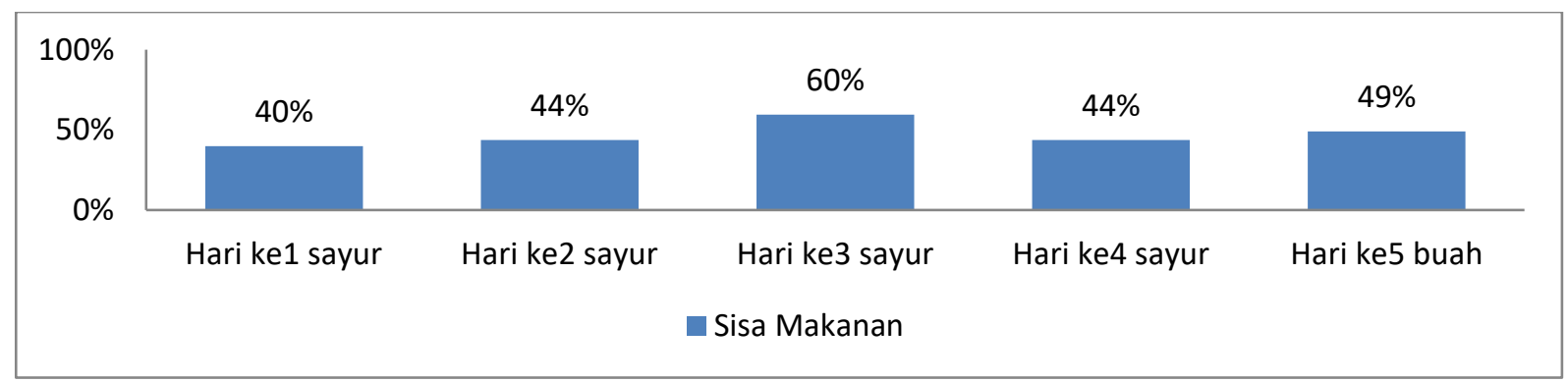

Gambar 1 Jumlah sisa sayur dan buah pada makan siang sekolah selama seminggu

Perbandingan jumlah konsumsi sayur dan buah untuk anak usia sekolah masih tergolong rendah. Pada siswa dengan jumlah konsumsi sayur dan buah kurang dari 5 porsi/hari mempunyai peluang berisiko menjadi obesitas sebesar 3,94 kali jika dibandingkan dengan siswa yang konsumsi lebih dari 5 porsi/hari. ${ }^{24}$ Konsumsi sayur dan buah pada anak dipengaruhi secara signifikan oleh pengetahuan anak, pendidikan orangtua, dan ketersediaan pangan. ${ }^{25}$

Meningkatkan jumlah porsi yang disajikan bisa menjadi salah satu alternatif untuk meningkatkan asupan sayur dan buah. ${ }^{26}$ Salah satu cara untuk meningkatkan konsumsi buah ialah dengan dibuat menjadi jus. ${ }^{27}$ Buah potong dan jus lebih banyak dipilih dan dikonsumsi dibandingkan buah utuh dan buah yang dikeringkan.
Sedangkan pada sayur lebih banyak pilih sayuran mentah yang dijadikan salad dibandingkan dengan sayur yang dimasak. ${ }^{28}$

Beberapa upaya yang dapat dilakukan pihak sekolah untuk membantu mengurangi sisa makanan diantarannya ialah meningkatkan kepedulian terhadap makanan karena makanan yang tersaji telah melalui proses yang panjang dari mulai penanaman, panen, pendistribusian, pemasakan hingga pemorsian pada tempat saji. Ketika makanan terbuang bukan hanya nilai gizi saja yang terbuang namun juga banyak hal lain yang terlibat seperti nilai ekonomi. ${ }^{29}$ Terdapat jumlah uang yang terbuang sekitar $26,1 \%$ dari total perencanaan makanan dan bila dikalkulasikan mencapai $\$ 432,349.30$

Tabel 3 Perbandingan rata-rata konsumsi sayur buah per hari dalam gram menurut anjuran

\begin{tabular}{lccccc}
\hline \multicolumn{2}{c}{ Bekal } & \multicolumn{3}{c}{ Makan Siang Sekolah } \\
& Rata-rata (gram) & \% anjuran WHO & $\begin{array}{c}\text { Rata-rata } \\
\text { (gram) }\end{array}$ & \% anjuran WHO & $p$ \\
\hline Makan Siang & 5,09 & 2 & 26,66 & 11 & $0,000^{*}$ \\
Sayur & 3,24 & 2 & 25,53 & 17 & $0,000^{*}$ \\
Buah & & & & & 0,322 \\
Sehari & 18,08 & 7 & 28,88 & 12 & 0,473 \\
Sayur & 25,46 & 17 & 31,81 & 21 & \\
Buah & & & & & \\
\hline
\end{tabular}

* signifikan bila $p<0,05$ makanan siang sekolah direkomendasikan untuk peningkatan sayur dan buah serta membatasi kalori yang berasal dari lemak jenuh dan natrium. Bekal makanan yang dibawa dari rumah masih belum bisa memenuhi seperti standar makan siang sekolah karena sering sekali ditemukan kalori tinggi yang berasal dari snack, kue manis dan minuman tinggi gula dan sedikit yang membawa sayur dan buah ${ }^{31}$. Di Indonesia masih belum ada standar acuan secara rinci untuk makan siang, hanya menyebutkan 30\% dari kecukupan. Berbeda dengan beberapa negara lain yang mempunyai standar makan siang sekolah melalui
National School Lunch Program ${ }^{10,17}$. Perlu adanya standar makanan yang diterapkan pada makan siang sekolah termasuk pada menu bekal yang harus dibawa seperti anjuran untuk membawa sayur dan buah setiap harinya Konsumsi sayur dan buah pada anak usia sekolah sangat penting, karena vitamin, mineral, serat dan zat mitronutrien lainnya dibutuhkan dalam masa tumbuh kembang anak. ${ }^{7}$ Konsumsi sayur dan buah dapat mengurangi faktor resiko kegemukan dimana hal ini bisa memicu penyakit degeneratif di usia dewasa seperti obesitas, hipertensi, stroke dan kardiovaskuler. ${ }^{5}$

\section{C2020. Zafira, Farapti. Open access under CC BY - SA license.}




\section{KESIMPULAN}

Berdasarkan hasil penelitian diketahui bahwa kelompok makan siang sekolah mengkonsumsi lebih banyak sayur dan buah saat makan siang dibanding keolompok bekal, namun tidak berbeda pada konsumsi sehari. Menurut anjuran WHO konsumsi sayur dan buah siswa masih rendah. Perlu adanya kebijakan yang mengatur standar acuan makan siang sekolah termasuk standar makanan bekal serta upaya untuk meningkatkan asupan dan mengurangi sisa sayur dan buah pada makanan siang sekolah.

\section{ACKNOWLEDGEMENT}

Penulis mengucapkan terima kasih kepada pihak SD Muhammadyah 4 Pucang Surabaya yang telah memberi izin penelitian dan dosen Departemen gizi FKM UNAIR atas bimbingan dan saran yang diberikan sehingga penulisan artikel ini dapat terselesaikan

\section{REFERENSI}

1. Badan Penelitian dan Pengembangan Kesehatan. Laporan Hasil Riset Kesehatan Dasar (Riskesdas) Indonesia tahun 2013. Riset Kesehatan Dasar 2013 (2013).

2. Badan Penelitian dan Pengembangan Kesehatan. Laporan Hasil Riset Kesehatan Dasar (Riskesdas) Indonesia tahun 2018. Riset Kesehatan Dasar 2018 (2019).

3. Badan Penelitian dan Pengembangan Kesehatan. Riset Kesehatan Dasar (RISKESDAS) 2013 dalam Angka Provinsi Jawa Timur. (2013).

4. Briawan, D. Gizi pada Anak Usia Sekolah. in IImu Gizi Teori \& Aplikasi (eds. Hardinsyah \& Supariasa, I. D. N.) (Penerbit Buku Kedokteran EGC, 2016).

5. Woodside, J. V., Young, I. S. \& McKinley, M. C. Fruit and vegetable intake and risk of cardiovascular disease. Proc. Nutr. Soc. 72, 399406 (2013).

6. Boeing, H. et al. Critical review: Vegetables and fruit in the prevention of chronic diseases. Eur. J. Nutr. 51, 637-663 (2012).

7. World Health Organization. Fruit and vegetable promotion initiative/a meeting report. Report of the meeting (2003).

doi:http://www.who.int/dietphysicalactivity/pu blications/f\&v_promotion initiative report.pdf

8. Tanaka, N. \& Miyoshi, M. School lunch program for health promotion among children in Japan. Asian Pacific J. Clin. Nutr. 21, 155-158 (2012).

9. Miyoshi, M., Nobuyo, T. \& Nishi, N. Schoolbased "Shokuiku" program in Japan: application to nutrition education in Asian countries. Asian Pacific J. Clin. Nutr. 21, 159162 (2012).

10. Smith, S. L. \& Cunningham-sabo, L. Food choice plate waste and nutrient intake of elementaryand middle-school students participating in the US National School Lunch Program. Public Health Nutr. 17, 1255-1263 (2013).

11. Crepinsek, M. K. A. Y., Gordon, A. R., Kinney, P. M. M. C. \& Condon, E. M. Meals Offered and
Served in US Public Schools. YJADA 109, S31S43 (2009).

12. Niaki, S. F., Moore, C. E., Chen, T.-A. \& Cullen, K. W. Younger Elementary School Students Waste\&nbsp;More School Lunch Foods than Older\&nbsp;Elementary School Students. J. Acad. Nutr. Diet. 117, 95-101 (2016).

13. Schwartz, M. B., Henderson, K. E., Read, M., Danna, N. \& Ickovics, J. R. New School Meal Regulations Increase Fruit Consumption and Do Not Increase Total Plate Waste. Child. Obes. 11, 242-247 (2015).

14. Ishdorj, A., Capps Jr., O., Storey, M. \& Murano, P. S. Investigating the Relationship between Food Pairings and Plate Waste from Elementary School Lunches. Food Nutr. Sci. 06, 1029-1044 (2015).

15. Thorsen, A. V. et al. Plate waste and intake of school lunch based on the new Nordic diet and on packed lunches: A randomised controlled trial in 8- to 11-year-old Danish children. J. Nutr. Sci. 4, 1-9 (2015).

16. Spiker, M. L., Hiza, H. A. B., Siddiqi, S. M. \& Neff, R. A. Wasted Food, Wasted Nutrients: Nutrient Loss from Wasted Food in the United States and Comparison to Gaps in Dietary Intake. J. Acad. Nutr. Diet. 117, 1031-1040.e22 (2017).

17. Byker, C., Rdn, S., Rd, J. B. \& Serrano, E. L. Food Waste in the National School Lunch Program 1978-2015: A Systematic Review. J. Acad. Nutr. Diet. 117, 1792-1807 (2017).

18. Upton, D., Upton, P. \& Taylor, C. Fruit and vegetable intake of primary school children: A study of school meals. J. Hum. Nutr. Diet. 25, 557-562 (2012).

19. Woo, T. The school meal system and schoolbased nutrition education in Korea. J. Nutr. Sci. Vitaminol. (Tokyo). 61, S23-S24 (2015).

20. Rees, G. A., Richards, C. J. \& Gregory, J. Food and nutrient intakes of primary school children : a comparison of school meals and packed lunches. 420-427 (2008). doi:10.1111/j.1365277X.2008.00885.X

21. Ellis, J. M., Galloway, A. T., Zickgraf, H. F. \& Whited, M. C. Picky eating and fruit and vegetable consumption in college students. Eat Behav. 30, 5-8 (2018).

22. Xue, Y. et al. Prevalence of picky eating behaviour in Chinese school-age children and associations with anthropometric parameters and intelligence quotient. A cross-sectional study. Appetite 91, 248-255 (2015).

23. Priyanti, S. Pengaruh Perilaku Makan Orang Tua Terhadap Kejadian Picky Eater (Pilih-Pilih Makanan Pada Anak Toddler Di Desa Karang Jeruk Kecamatan Jatirejo Mojokerto. Medica Majapahit 5, 43-55 (2013).

24. Nuraeni, I., Hadi, H. \& Paratmanitya, Y. Perbedaan konsumsi buah dan sayur pada anak sekolah dasar yang obes dan tidak obes di Kota Yogyakarta dan Kabupaten Bantul. J. Gizi dan Diet. Indones. (Indonesian J. Nutr. Diet. 1, 81 (2016). 
25. Mohammad, A. \& Madanijah, S. Konsumsi Buah Dan Sayur Anak Usia Sekolah Dasar Di Bogor. J. Gizi dan Pangan 10, 71-76 (2015).

26. Miller, N. et al. Increasing portion sizes of fruits and vegetables in an elementary school lunch program can increase fruit and vegetable consumption. Appetite 91, 426-430 (2015).

27. Evans, C. E. L., Christian, M. S., Cleghorn, C. L., Greenwood, D. C. \& Cade, J. E. Systematic review and meta-analysis of school-based interventions to improve daily fruit and vegetable intake in children aged 5 to 12 y. $A m$. J. Clin. Nutr. 96, 889-901 (2012).

28. Handforth, K., Gilboy, M. B., Harris, J. \& Melia, N. Fruit and Vegetable Plate Waste among Students in a Suburban School District
Participating in the National School Lunch Program. J. Child Nutr. Manag. 40, (2016).

29. Bloom, J. Schooling Food Waste: How Schools Can Teach Kids to Value Food. Food Tank (2016).

30. Cohen, J.F.W., Richardson, S., Austin, S.B., Economos, C.D. and Rimm, E. B. School Lunch Waste among Middle School Students: Implications for Nutrients Consumed and Food Waste Costs. Am. J. Prev. Med. 44, 114-121 (2013).

31. Minaya, S. \& Rainville, A. J. How Nutritious Are Ch ildren's Packed School Lunches? A Comparison of Lunches Brought From Home and School Lunches. (2012). 